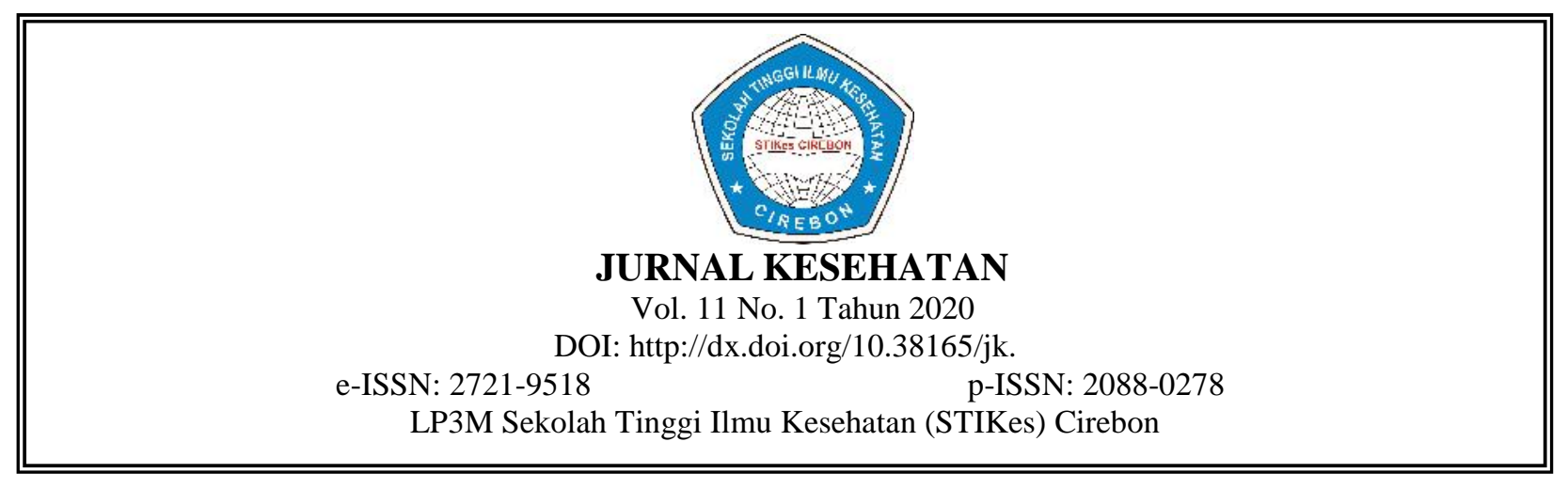

\title{
HUBUNGAN TINGKAT INSOMNIA DENGAN KUALITAS HIDUP PADA LANSIA YANG HIDUP SENDIRI
}

\author{
Mustopa* \\ Program Studi Ilmu Keperawatan, Sekolah Tinggi Ilmu Kesehatan Cirebon \\ perawatmandiri.com@gmail.com \\ Muhammad Kamaludin ** \\ Program Studi Ilmu Keperawatan, Sekolah Tinggi Ilmu Kesehatan Cirebon \\ Rahmawaty Neny Triatny ${ }^{* * *}$ \\ Program Studi Ilmu Keperawatan, Sekolah Tinggi Ilmu Kesehatan Cirebon
}

\begin{abstract}
Abstrak
Lansia banyak menghadapi berbagai masalah kesehatan yang perlu penanganan segera dan terintegrasi seperti insomnia. Insomnia merupakan suatu keadaan yang menggambarkan seseorang tidak memiliki kualitas hidup yang baik sehingga merasa tidak cukup tidur, meskipun mempunyai pola waktu tidur yang baik, akan tetapi dengan keadaan tersebut menyebabkan seseorang tidak tampak segar untuk menjalankan aktifitas sehari-hari pada siang hari. Kualitas hidup diartikan sebagai persepsi individu mengenai berfungsinya mereka di dalam bidang kehidupan. Adapun tujuan penelitian ini untuk mengidentifikasi tingkat insomnia, untuk mengetahui kualitas hidup lansia dan mencari hubungan antara tingkat insomnia dengan kualitas hidup lansia yang hidup sendiri.

Metode penelitian ini adalah korelasi yang bersifat deskriptif, dengan menggunakan pendekatan crossectional. Populasi dalam penelitian ini adalah seluruh lansia yang mengalami insomnia di Wilayah Kerja Puskesmas Kaliwedi dengan jumlah sampel sebanyak 42 lansia dengan metode pengambilan data total sampling. Tingkat insomnia diukur dengan IRS (Insomnia Rating Scale) dan kualitas hidup diukur dengan WHOQOL-BREF. Hasil penelitian dengan hasil uji statistik chi-square diperoleh $p$ value $(0,001)<=0,05$ (lebih kecil dari 0,05). Hal tersebut menunjukkan bahwa $\mathrm{H}_{0}$ (Hipotesis Nol) ditolak dan $\mathrm{H}_{\mathrm{a}}$ (Hipotesis Alternatif) diterima.

Berdasarkan hasil penelitian tersebut maka dapat disimpulkan bahwa ada hubungan antara tingkat insomnia dengan kualitas hidup Lansia yang hidup sendiri di Wilayah Kerja Puskesmas Kaliwedi Kabupaten Cirebon.
\end{abstract}

Kata Kunci: Lansia, insomnia, kualitas hidup

\begin{abstract}
Many elderly face many health issues that need immediate handling and integrated such as insomnia. Insomnia is a State that describes a person does not have a good quality of life so feel not enough sleep, despite having a good sleep pattern, but with the circumstances cause someone didn't look fresh to run day-to-day activities during the day. Quality of life is defined as an individual's perception about their functioning in the areas of life. As for the purpose of this research was to identify the level of insomnia, to know the quality of life of the elderly and looking for the relationship between the level of insomnia with the quality of life of the elderly who live alone.

The method of this research is the correlation that is descriptive, using the crossectional approach. The population in this research is the entire elderly who experience insomnia Clinics in the region Kaliwedi with the number of samples as much as 42 elderly with total data retrieval method of sampling. The level of insomnia is measured by the IRS (Insomnia Rating Scale) and quality of life measured by the WHOQOL-BREF. Research results with the results of the
\end{abstract}


statistical test of chi-square obtained $p$ value $(0.001)=0.05<$ (less than 0.05). This indicates that HO (Zero Hypothesis) was rejected and Ha (alternative hypothesis) is received.

Based on the results of the study can be concluded there is a connection between the level of insomnia with the quality of life of the elderly who live alone in the region of Cirebon district health centers Work Kaliwedi.

Keywords: Elderly, insomnia, quality of life 


\section{PENDAHULUAN}

Menua adalah proses menurunya secara perlahan-lahan kekuatan jaringan untuk memperbaiki atau mengganti dan mempertahankan fungsi normalnya sehingga lemah kemampuan terhadap infeksi dan memperbaiki kerusakan. Proses ini merupakan proses yang terus-menerus (berlanjut) secara alamiah. Dimulai sejak lahir dan umumnya dialami semua mahluk hidup. Dalam prosesnya setiap individu dalam organ tubuh juga tidak sama. Ada kalanya orang belum tergolong lanjut usia (masih muda) tetapi mengalami kekurangan-kekurangan yang mencolok. ${ }^{1}$

Lansia yang hidup sendiri dan mengalami kondisi kesepian menjadi salah satu indikator utama dari kesejahteraan tetapi telah dikaitkan dengan masalah kesehatan fisik dan mental, tekanan emosional, depresi, penurunan kognitif dan kualitas hidup yang lebih buruk. Lansia dengan hidup sendiri lebih rentan dan cenderung diabaikan sehingga muncul beberapa permasalahan yang berbeda. $^{2}$

Tidur merupakan suatu proses otak yang di butuhkan oleh seseorang untuk dapat berfungsi dengan baik. Masyarakat awam belum begitu mengenal gangguam tidur sehingga jarang mencari pertolongan. Beberapa gangguan tidur dapat mengancam jiwa, baik secara langsung (misalnya insomnia yang bersifat keturunan dan fatal seperti apnea tidur obstruktif) maupun yang bersifat tidak langsung misalnya kecelakaan akibat gangguan tidur. ${ }^{3}$

Insomnia lebih umum menurunkan kualitas hidup pada individu lansia ini dengan gangguan-gangguan tidur dan penyebab gangguan tidur lainya dari faktor determinan aspek fisik, psikologis, lingkungan dan aspek sosial. ${ }^{4}$ insomnia pada lansia memiliki pengaruh dampak terhadap kualitas individu dan sosial yang cukup dalam dan kondisi ini membutuhkan terapi tambahan perilaku kognitif agar klien dapat beradaptasi terhadap kognitifnya. ${ }^{5}$

Ketidakcukupan kualitas tidur dapat menyebabkan rusaknya memori dan kemampuan kognitif. Apabila hal ini terus berlanjut hingga bertahun-tahun dapat berdampak pada tekanan darah tinggi, stroke, serangan jantung, hingga masalah psikologis serta depresi dan gangguan perasaan lain. Apabila hal ini berlangsung pada waktu yang lama, dapat menyebabkan seseorang mengalami kurang tidur yang mengakibatkan resiko penyakit yang dideritanya. ${ }^{5}$

Berdasarkan studi pendahuluan yang dilakukan oleh peneliti, di wilayah Kerja Puskesmas Kaliwedi. Data yang diperoleh selama 3 bulan terakhir, pasien lansia yang berobat ke Puskesmas Kaliwedi sejumlah 197 pasien lansia, dan berdasarkan informasi dari perawat pelaksana program lansia pasien yang mengalami keluhan kesulitan untuk tidur sebanyak 42 pasien lansia, di usianya yang menjadi tua terjadi masalah gangguan tidur sehingga lansia merasa cemas, gelisah, lemah, letih dan kurang tenaga setelah tidur.

Berdasarkan latar belakang diatas, peneliti merasa tertarik melakukan penelitian untuk mengetahui Hubungan Antara Tingkat Insomnia Dengan Kualitas Hidup Pada Lansia Yang Hidup Sendiri di Wilayah Kerja Puskesmas Kaliwedi Kabupaten Cirebon.

\section{METODE PENELITIAN}

Metode penelitian ini adalah kolerasi yang bersifat deskriptif, dengan menggunakan pendekatan crossectional. Penelitian ini mempelajari tentang tingkat insomnia dengan kualitas hidup lansia yang hidup sendiri dengan cara pendekatan observasi atau pengumpulan data sekaligus pada satu waktu (point time approach). Tiap subjek penelitian hanya diobservasi sekali saja dan pengukuran dilakukan terhadap variabel subjek pada saat pemeriksaan. Variabel adalah bahwa variabel merupakan karakteristik subjek penelitian yang berubah dari satu subjek ke subjek lainnya. Variabel Independent dalam penelian ini adalah tingkat insomnia.Variabel Dependent dalam penelitian ini adalah kualitas hidup lansia.

.Populasi dalam penelitian ini adalah seluruh lansia yang mengalami insomnia berjumlah 42 lansia. Teknik pengambilan sampel menggunakan Total Sampling. ialah keseluruhan dari lansia yang memenuhi kriteria inklusi di Wilayah Kerja Puskesmas Kaliwedi Kabupaten Cirebon sejumlah 42 lansia.

.Dalam penelitian keperawatan, kriteria sampel meliputi kriteria ekslusi, dimana kriteria tersebut menentukan dapat dan tidaknya sampel yang tersebut digunakan. 
1. Kriteria Inklusi

1) Lansia usia $>45$ tahun hidup sendiri

2) Bersedia menjadi responden

3) Memiliki Gangguan insomnia

4) Mampu melakukan komunikasi dengan baik

2. Kriteria Ekslusi

1) Memiliki penyakit kronis

2) Memiliki gangguan psikosial

3) Tidak sedang mengkomsumsi obat insomnia

Instrumen atau alat-alat dalam penelitian ini adalah lembar kuesioner untuk tingkat insomnia dan untuk mengukur kualitas hidup lansia yang mengalami hidup sendiri menggunakan lembar penilaian kuesioner WHOQOL-BREF dengan kriteria kualitas hidup buruk dengan skor 0-50 dan kualitas hidup baik dengan skor 51-100 dan kuesioner IRS (insomnia rating scale) dengan kriteria tidak insomnia dengan skor 11-19, Insomnia ringan dengan skor 20-27, Insomnia sedang 28-36, dan Insomnia berat dengan skor 37-44.

\section{HASIL PENELITIAN}

Hasil penelitian dengan judul Hubungan Antara Tingkat Insomnia Dengan Kualitas Hidup Pada Lansia Yang Hidup Sendiri di Wilayah Kerja Puskesmas Kaliwedi Kabupaten Cirebon Tahun. Penelitian dilakukan selama kurang lebih 3 minggu dengan jumlah sampel penelitian yang diambil dengan teknik total sampling yaitu berjumlah 42 responden yang telah ditentukan berdasarkan kriteria inklusi.

\section{Tingkat Insomnia}

Tabel 1. Distribusi Frekuensi Tingkat Insomnia Pada Lansia yang Hidup Sendiri di Wilayah Kerja Puskesmas Kaliwedi Kabupaten Cirebon

\begin{tabular}{cccc}
\hline Gejala Insomnia & $\mathrm{n}$ & \multicolumn{2}{c}{ Presentase (\%) } \\
\hline Insomnia ringan & 14 & 33,3 & \\
Insomnia sedang & 23 & 54,8 \\
Insomnia Berat & 5 & 11,9 \\
\hline Total & 42 & 100 \\
\hline
\end{tabular}

Berdasarkan tabel 1. menunjukkan bahwa seluruh sampel mengalami insomnia sebanyak 42 lansia (100\%). Pada sampel penelitian yang berjumlah 42 lansia menunjukkan bahwa sampel dengan insomnia ringan sebanyak 14 lansia (33,3\%), insomnia sedang sebanyak 23 lansia (54,8\%), dan insomnia berat sebanyak 5 orang $(11,9 \%)$.

\section{Kualitas Hidup Lansia}

Tabel 2. Distribusi Frekuensi Kualitas Hidup Lansia yang Hidup Sendiri di Wilayah Kerja Puskesmas Kaliwedi Kabupaten Cirebon

\begin{tabular}{cccc}
\hline Kualitas Hidup & & $\mathrm{n}$ & Presentase (\%) \\
\hline Baik & 10 & & 23,8 \\
Buruk & & 32 & 76,2 \\
\hline Total & & 42 & 100 \\
\hline
\end{tabular}

Berdasarkan tabel 2 menunjukkan bahwa lansia yang berada di Wilayah Kerja Puskesmas Kaliwedi Kabupaten Cirebon cenderung mengalami kualitas hidup buruk sebanyak 32 lansia 
(76,2\%). Distribusi frekuensi kualitas hidup lansia diukur dengan kuesioner WHOQOL-BREF yang terdiri dari 26 pertanyaan. Pada sampel penelitian yang berjumlah 42 lansia menunjukkan bahwa sampel dengan kualitas hidup baik sebanyak 10 lansia $(23,8)$, sedangkan sampel yang memiliki kualitas hidup buruk sebanyak 32 lansia $(76,2 \%)$.

\section{Hubungan antara tingkat insomnia dengan kualitas hidup lansia}

Tabel 3. Hubungan Antara Tingkat Insomnia Dengan Kualitas Hidup Lansia yang Hidup Sendiri di Wilayah Kerja Puskesmas Kaliwedi Kabupaten Cirebon

\begin{tabular}{|c|c|c|c|c|c|c|c|}
\hline \multirow[t]{3}{*}{ Tingkat Insomnia } & \multicolumn{4}{|c|}{ Kualitas Hidup } & \multirow{3}{*}{$\mathrm{n}$} & \multirow{3}{*}{$\%$} & \multirow[t]{3}{*}{$P$ Value } \\
\hline & \multicolumn{2}{|c|}{ Baik } & \multicolumn{2}{|c|}{ Buruk } & & & \\
\hline & $\mathrm{n}$ & $\%$ & $\mathrm{n}$ & $\%$ & & & \\
\hline Insomnia ringan & 8 & 57,1 & 6 & 42,9 & 14 & 100 & \\
\hline Insomnia sedang & 2 & 8,7 & 21 & 91,3 & 23 & 100 & 0,001 \\
\hline Insomnia berat & 0 & 0 & 5 & 100 & 5 & 100 & \\
\hline Total & 10 & & 32 & & 42 & & \\
\hline
\end{tabular}

Hasil dapat lihat bahwa responden lansia di Wilayah Kerja Puskesmas Kaliwedi Kabupaten Cirebon yang memiliki insomnia ringan dengan kualitas hidup baik yaitu dengan jumlah 8 lansia $(57,1 \%)$ dan kualitas hidup buruk bahkan lebih kecil yaitu 6 lansia $(42,9 \%)$, dan responden yang memiliki insomnia sedang dengan kualitas hidup baik terdapat 2 lansia $(8,7 \%)$ sedangkan yang memiliki hidup buruknya sebanyak 21 lansia $(91,3 \%)$, adapun responden dengan insomnia berat semuanya memiliki kualitas hidup buruk sebanyak 5 lansia (100\%) tidak ada satupun yang memiliki kualitas hidup baik. Hasil uji statistik dengan metode chi-square untuk insomnia dengan kualitas hidup menunjukkan $P$ value $0,001<0,05$.

Hal tersebut menunjukkan bahwa $\mathrm{H}_{0}$ (Hipotesis Nol) ditolak dan $\mathrm{H}_{\mathrm{a}}$ (Hipotesis Alternatif) diterima maka dapat disimpulkan hal ini menunjukkan bahwa terdapat adanya hubungan yang signifikan antara tingkat insomnia dengan kualitas hidup lansia yang hidup sendiri di Wilayah Kerja Puskesmas Kaliwedi Kabupaten Cirebon Tahun 2018.

\section{PEMBAHASAN}

Penelitian ini telah menunjukkan bahwa variabel independent berupa tingkat insomnia mempunyai hubungan yang signifikan dengan variabel dependent yaitu kualitas hidup lansia di wilayah kerja Puskesmas Kaliwedi Kabupaten Cirebon. Hal ini sejalan dengan dengan penelitian yang telah di lakukan oleh Olfson, Wall, Min Liu, Morin, \& Blanco ( 2018) bahwa insomnia sangat lazim dan terkait dengan beban tingkat populasi, kondisi kesehatan umum, rasa sakit dalam kondisi penyakit serta peristiwa tekanan gangguan mental dan menpengaruhi kualitas hidup. ${ }^{6}$

Kesepian karna hidup sendiri melibatkan aspek psikologis dan sosial, ada korelasi antara skor kesepian yang tinggi dan risiko pelecehan yang lebih tua. Kesepian berhubungan dengan tekanan emosional, depresi, penurunan kognitif dan kualitas. Menjadi sendiri di usia lanjut tidak hanya memiliki masalah kesehatan dan perawatan jiwa, tetapi juga terkait dengan masalah spiritual. ${ }^{2}$

Jenis kelamin juga menjadi salah satu faktor yang berhubungan dengan penyebab terjadinya insomnia. Pada penelitian ini didapatkan perempuan lebih banyak mengalami insomnia dibandingkan dengan laki-laki, yaitu keseluruhan lansia yang berjenis kelamin perempuan sebanyak 23 lansia $(54,2 \%)$ dan laki-laki hanya 19 lansia $(45,8 \%)$ yang mengalami insomnia. Selaras dengan sebuah riview yang di lakukan oleh Zhang \& Wing ( 2006) perempuan lebih tinggi dalam risiko insomnia baik dalam penelitian besar maupun penelitian lokal. Kecenderungan kecenderungan gender perempuan ini adalah konsisten dan menyeluruh di semua usia, namun lebih signifikan pada usia lebih tua. Meskipun perempuan demikian jelas risiko insomnia ada di berbagai daerah, namun ada perbedaan pada perempuan yang di Asia Timur angka kejadian insomnia lebih rendah dan hal ini masih di perlukan studi lebih dalam lagi. ${ }^{7}$

Meskipun studi penilaian qualitas hidup pada lansia sangat penting sebagai sumber data peningkatan kualitas hidup, namun hasil studi yang di lakukan oleh Vanleerberghe, Witee, Claes, 
Shalock, \& Verte (2017) mengungkapkan bahwa hal ini sangat jarang di lakukan. Hanya sebagian kecil dari studi yang melaporkan penilaian kualitas hidup, termasuk instrumen yang digunakan dan hasilnya. Sehingga studi kualitas hidup khusus lansia sebaiknya terus di kembangkan sesuai dengan perkembangan permasalahan lansia saat ini. 8

\section{SIMPULAN}

Berdasarkan data hasil penelitian yang telah diuraikan peneliti, oleh karena itu dapat diambil simpulan bahwa :

1) Tingkat insomnia pada lansia dengan insomnia sedang/berat dengan frekuensi yaitu 28 lansia $(66,7 \%)$ dominan lebih banyak dibandingkan dengan insomnia ringan dengan frekuensi 14 lansia $(33,3 \%)$.

2) Kualitas hidup pada lansia dengan insomnia sebagian besar mengalami kualitas hidup buruk dengan frekuensi 32 lansia $(76,2 \%)$ dan yang memiliki kualitas hidup baik hanya 10 lansia $(23,8 \%)$.

3) Terdapat hubungan antara tingkat insomnia dengan kualitas hidup lansia yang hidup sendiri di Wilayah Kerja Puskesmas Kaliwedi Kabupaten Cirebon dengan nilai P value 0,001.

\section{SARAN}

Adapun saran- saran yang dapat diberikan peneliti adalah sebagai berikut:

Perlu penelitian lebih lanjut untuk melihat hubungan antara tingkat insomnia dengan kualitas hidup lansia dengan mengidentifikasi penyebab terjadinya insomnia pada lansia

\section{DAFTAR PUSTAKA}

1. Muhith A, Siyoto S. Pendidikan Keperawatan Gerontik. 1st ed. Cristian P, editor. Yogjakarta: ANDI OFSET; 2016. 25 p.

2. Zerrin E, Nergis C. The problem of elderly people who live alone: An elderly neglect case. Turk Geriatr Derg. 2014;17(1):99-102.

3. Priyoto, Lestari PP. Nursing Intervention Classification (NIC) dalam keperawatan Gerontik. 1st ed. Jakarta: Salemba Medika; 2015. 67 p.

4. Lasisi AO, Gureje O. Prevalence of insomnia and impact on quality of life among community elderly subjects with tinnitus. Ann Otol Rhinol Laryngol. 2011;120(4):226-30.

5. Abad VC, Guilleminault C. Insomnia in Elderly Patients: Recommendations for Pharmacological Management. Drugs and Aging [Internet]. 2018;35(9):791-817. Available from: https://doi.org/10.1007/s40266-018-0569-8

6. Olfson M, Wall M, Min Liu S, Morin CM, Blanco C. Insomnia and Impaired Quality of Life in the United States. Clin Psyciatry [Internet]. 2018;79 no(5). Available from: https://www.psychiatrist.com/JCP/article/Pages/2018/v79/17m12020.aspx

7. Zhang B, Wing YK. Sex Differences in Insomnia: A Meta-Analysis. Sleep [Internet]. 2006;29.

Available

from: ttps://pubmed.ncbi.nlm.nih.gov/16453985/?from_term=((Insomnia)+AND+(elderly))+AND+ (sex)\&from_pos=1

8. Vanleerberghe P, Witee N de, Claes C, Shalock R, Verte D. The Quality of Life of Older People Aging in Place: A Literature Review. Qual Life [Internet]. 2017; Available from: https://pubmed.ncbi.nlm.nih.gov/28707047/?from_term=+\%28elderly\%29\%29+AND+\%28q uality+of+life $\% 29 \&$ from_pos=3 